\title{
Evaluation of Ginkgo biloba and Flunixin in BIM Gene Expression and Viability of Ovarian Cancer Cell A2780s
}

\author{
Farnoosh Soleamani ${ }^{1}$, Elham Salehi (Did ${ }^{1,}{ }^{*}$, Majid Morovati-Sharifabad (iD) ${ }^{1}$, Fatemeh Sarkargar ${ }^{2}$ and \\ Gholamhosein Pourghanbari ${ }^{3}$ \\ ${ }^{1}$ Department of Basic Sciences, Faculty of Veterinary Medicine, Ardakan University, Ardakan, Iran \\ ${ }^{2}$ Expert Laboratory of Genetic, Meybod Genetic Research Center, Meybod, Iran \\ ${ }^{3}$ Department of Clinical Sciences, Faculty of Veterinary Medicine, Ardakan University, Ardakan, Iran \\ "Corresponding author: Department of Basic Sciences, Faculty of Veterinary Medicine, Ardakan University, Ardakan, Iran. Email: esalehi@ardakan.ac.ir
}

Received 2021 April 04; Revised 2021 July 25; Accepted 2021 July 26.

\begin{abstract}
Background: Ovarian cancer is the deadliest gynecologic cancer. Studies on the therapeutic properties of Ginkgo biloba and flunixin showed that these drugs, singly or in combination with other drugs, have anti-cancer activities. Different genes are involved in apoptosis regulation. The BIM gene is one of the most important regulators of this process. BIM has different roles, including cell cycle regulation, apoptosis induction, deoxyribonucleic acid recombination, chromosomal segregation, and cell aging.

Methods: This study evaluated the viability percentage of the A2780s cell line with Ginkgo biloba and flunixin at different concentrations, compared to that of the control group. Then, the half-maximal inhibitory concentration (IC50) values of Ginkgo biloba and flunixin were determined within $24 \mathrm{~h}$. Then, the expression of the BIM gene was evaluated using a real-time polymerase chain reaction (PCR).

Results: The IC50 results showed that Ginkgo biloba and flunixin significantly reduced cell life $(\mathrm{P}<0.01)$ depending on time and concentration. The results of real-time PCR showed that cell treatment with Ginkgo biloba and flunixin significantly increased BIM expression.

Conclusions: The results of this experiment indicated that BIM gene expression was increased in cancer cells treated with Ginkgo biloba and flunixin, compared to that reported for control cells. Therefore, with further research in the future, these compounds can be used for the development of ovarian anti-cancer drugs.
\end{abstract}

Keywords: Ginkgo biloba, Flunixin, BIM, Ovarian Cancer, Apoptosis

\section{Background}

Ovarian malignancy is one of the most common causes of death concerning female reproductive system cancers $(1,2)$. Patients undergo surgery and receive chemotherapy with a drug containing platinum (3). Today, the use of safer alternatives, such as herbal remedies for cancer, has increased. Ginkgo biloba is a herbal medicine showing anti-cancer effects $(4,5)$. Effective compounds of this plant include flavonoid glycosides and their antioxidant properties (6). The administration of drugs that have previously been used to treat noncancerous diseases is another strategy to overcome the side effects of chemotherapy, pharmacodynamic, pharmacokinetic, and toxicity properties of which are well known (7).

Flunixin can act as a nonselective inhibitor of cyclooxygenases because it is a chemical compound, antiinflammatory, and nonsteroidal. Flunixin is also used as an analgesic and antipyretic drug in medicine and exerts its inflammation effect by inhibiting the production of prostaglandins. The effect of flunixin has been confirmed in the treatment of gynecological cancer in rats $(7,8)$. The BIM gene is one of the most important genes in the internal pathway or apoptosis. In addition to the known role in apoptosis induction, BIM is in the physiology of cell survival during evolution. BIM plays an essential role in the homeostasis of leukocytes and the prevention of their processes. The BIM gene is divided into three isoforms (ie, BimEL, BimL, and BimS), all of which are classified as BH3only. The properties of pro-apoptotic-only genes, such as $B I M$, are connected to anti-apoptotic protein and are then allowed to form BAX pro-apoptotic and BAK to form channels on the mitochondrial membrane, which cause the release of cytochrome $C$ and apoptosis (9). 


\section{Objectives}

This study aimed to determine the effects of flunixin and Ginkgo biloba on the viability and apoptosis of ovarian cancer cells in the A2780s cell line.

\section{Methods}

\subsection{Cell Culture}

For this experiment, the A2780s cell line (Pasteur Institute, Iran, NCBI code: C461) was used. RPMI 1640 medium with 10\% (fetal bovine serum) serum and 1\% PenStrep (ie, penicillin-streptomycin antibiotic solution) were used for cell culture and then incubation. The cell density was estimated under a microscope after 3 to 4 days, and the cells were transferred to a new flask when the density reached $70-80 \%$.

\subsection{Drug}

For this study, $100 \mathrm{mg} / \mathrm{mL}$ flunixin solution was purchased from Rooyan Darou Pharmaceutical Company, Iran. Then, 50 and $100 \lambda$ flunixin were dissolved in phosphatebuffered saline (PBS) medium for serial dilutions. Additionally, Ginkgo biloba tablets were purchased from Vitarmonil Darou Pharmaceutical Company, Iran, as 100 $\mathrm{mg} / \mathrm{mL}$. For 100, 50, and $25 \lambda$ dilutions, Ginkgo biloba was dissolved in standard saline solution.

\subsection{Cell Preparation}

\subsubsection{IC50 Method}

After $24 \mathrm{~h}$ of incubation under optimum conditions, for calculating the half-maximal inhibitory concentration (IC50), different doses of flunixin and Ginkgo biloba were added to each well. The well was first washed with PBS after $24 \mathrm{~h}$, and then the cells were removed from the plates by trypsinizing them. Then, $50 \mu \mathrm{L}$ of the cell solution and $50 \mu \mathrm{L}$ of trypan blue (vital dye) were poured into the microtubule to count. Then, about $10 \mu \mathrm{L}$ of the solution was poured on the Neobar slide.

\subsubsection{Cell Culture}

First, the cells were cultured in 24-well plates. Ginkgo biloba and flunixin were each added at a dose of $100 \mathrm{mg}$ to target well after $24 \mathrm{~h}$ of cell attachment. Cells receiving only one drug, cells receiving both drugs at the same time. For the preservation of the ribonucleic acid (RNA) of the cells, cell plaques were rapidly transferred to a nitrogen tank. In the case of combination drugs, some of them were applied in a specific schedule and, after $24 \mathrm{~h}$ from the first drug to the second drug, regularly changed every 24 h. Moreover, the drug was added to the culture medium again.

\subsection{Molecular Section}

\subsubsection{RNA Isolation}

The isolation of RNA was performed based on the High Pure RNA Isolation Kit (Roche Life Science, Germany) guidelines. Electrophoresis was performed on an agarose gel to ensure the quality of the extracted RNA. The presence of two clear bands on the gel confirmed the health of the extracted RNA. Furthermore, optical absorption ratios of 260/280 and 260/230 nm were obtained using NanoDrop.

\subsection{2. cDNA Synthesis}

Complementary deoxyribonucleic acid (cDNA) synthesis was performed based on the Thermo Scientific Kit protocol. Accordingly, $1 \mu \mathrm{L}$ RNA, $1 \mu \mathrm{L}$ Random Hexamer, and $6 \mu \mathrm{L}$ diethyl pyrocarbonate water were mixed, spun, and incubated in a thermal cycler for $5 \mathrm{~min}$ at $65^{\circ} \mathrm{C}$. Then, $4 \mu \mathrm{L}$ $5 \mathrm{x}$ Reaction Buffer, $2 \mu$ L deoxyribonucleotide triphosphate, and $1 \mu \mathrm{L}$ RT enzyme were added and reached the final volume of $20 \mu \mathrm{L}$ with deionized distilled water (DDW). The temperature-time program was performed at $25^{\circ} \mathrm{C}$ for 10 min, $42^{\circ} \mathrm{C}$ for $60 \mathrm{~min}$, and $65^{\circ} \mathrm{C}$ for $10 \mathrm{~min}$. The synthesized cDNA quality was ensured using NanoDrop.

\subsubsection{Primer Design}

Dedicated primers were designed by the Gene Runner Software (version 6.5.52) and blasted by NCBI (Table 1 ).

\begin{tabular}{cccc}
\hline \multicolumn{4}{c}{ Table 1. Primer Sequence for Real-Time Polymerase Chain Reaction } \\
\hline Primer Name & Sequence (5' to 3') & Tm & Amplicon Size \\
\hline GAPDH & & 102 \\
F & TCCTCCACCTTTGACGCTG & 53.3 & \\
R & CACCACCCTGTTGCTGTAGC & 52.9 & \\
BIM & & & 145 \\
F & GAAGGCAATCACGGAGGTG & 52.7 & \\
R & AGGATCGAGACAGCAGGGAG & 53.3 & \\
\hline
\end{tabular}

\subsubsection{Investigation of Gene Expression}

For real-time polymerase chain reaction (PCR), SYBR Green Master Mix (Applied Biosystems, Warrington, UK) was used. Accordingly, $10 \mu \mathrm{L}$ SYBR green, $1 \mu \mathrm{L}$ of forward and reverse primers of each gene, and $5 \mu \mathrm{L}$ cDNA were mixed and reached the final volume of $20 \mu \mathrm{L}$ with DDW. The temperature-time program was performed at $95^{\circ} \mathrm{C}$ for $1 \mathrm{~min}, 60^{\circ} \mathrm{C}$ for $15 \mathrm{sec}$, and $60^{\circ} \mathrm{C}$ for $60 \mathrm{sec}$. The melting curve was investigated to ensure the specificity of the product. All the experiments in this study were repeated three times. Gene expression was measured by the $2^{-\Delta \Delta \mathrm{Ct}}$ method. 


\subsection{Statistical Analysis}

After measuring the gene expression by the $2^{-\Delta \Delta \mathrm{Ct}}$ method and using Excel software (version 2.16), the data were obtained from real-time PCR, and viability assay sections were performed using SPSS software (version 25), one-way analysis of variance, Tukey's test, and CompuSyn software (version 1.0.1). A p-value of less than 0.01 was considered the significant level.

\section{Results}

\subsection{IC50 Method}

A2780 cells were cultured at 25, 50, and $100 \mu \mathrm{m}$ Ginkgo biloba and 50 and $100 \mu \mathrm{m}$ flunixin concentrations in $24 \mathrm{~h}$. The results showed that after $24 \mathrm{~h}$ of incubation, the reduction of Ginkgo biloba and the survival rate of flunixin were dose-dependent (Figures 1 and 2). Accordingly, the number of living cells, compared to that of the control group (mean \pm standard deviation), was significantly reduced from a concentration of 50 to $100 \mu \mathrm{m}$.

The bioavailability decreased with increasing the concentrations of Ginkgo biloba and flunixin in the A2780s cell line after $24 \mathrm{~h}$ of incubation. The bioavailability of both drugs was significantly reduced from $97.5 \%$ to less than 50\%. According to Figure 2, IC50 for Ginkgo biloba, and flunixin was, which was followed by the experimental process using $100 \mu \mathrm{m}$ concentration. Tukey's test showed a significant difference between doses of 50 and $100 \mu \mathrm{m}$ in the treatment group; however, the concentration of living cells was significantly reduced from 50 to $100 \mu \mathrm{m}$, compared to that reported for the control group.

\subsection{Investigation of Cell Viability at Different Times}

The results in Figure 3 showed that the treatment with Ginkgo biloba and flunixin affected A2780s cell viability using the best dose of the inhibitor $(100 \mu \mathrm{m})$.

At this dose, cell viability significantly reduced in comparison to witness cells at $72 \mathrm{~h}$. treatment with Ginkgo biloba. Cell viability decreased over time. Different times showed numerous differences $(\mathrm{P}<0.01)$; however, the highest lethality according to Ginkgo biloba and flunixin was in $24 \mathrm{~h}$. There was no significant relationship between the treatment group and Ginkgo biloba, and flunixin at 24, 48 , and 72 h in Tukey's test; nevertheless, it was significant in comparison to the control group $(\mathrm{P}<0.01)$. The combination index $(\mathrm{CI})$ values were determined using CompuSyn software.

\subsection{BIM Gene Expression}

In this study, BIM gene expression was increased in the A2780s cell line treated with Ginkgo biloba and flunixin, compared to that reported for the control cells (Figure 4). The rate of expression increase in Ginkgo-biloba-treated cells for $48 \mathrm{~h}$ was higher than those treated with Ginkgo biloba for $24 \mathrm{~h}$ (Figure 4 ). After $24 \mathrm{~h}$ of treatment, Ginkgo biloba and flunixin increased BIM gene expression (Figure 4). The CI of synergistic effects between Ginkgo biloba and flunixin was analyzed using CompuSyn software. Accordingly, $100 \mu \mathrm{m}$ flunixin had synergistic effects $(\mathrm{CI}<7.3)$ with Ginkgo biloba and strong synergistic effects $(\mathrm{CI}<11.0)$ with Ginkgo biloba on flunixin (Figure 5).

\section{Discussion}

The present study investigated the effects of flunixin and Ginkgo biloba on the ovarian cancer viability of the human A2780s cell line. In this study, flunixin and Ginkgo biloba were administered for 24,48 , and $72 \mathrm{~h}$ in the cell line. Cell viability decreased over time; however, most deaths occurred within $24 \mathrm{~h}$ (50\%; Figure 3). The results showed that the use of $50 \mu \mathrm{m}$ of flunixin and Ginkgo biloba in 24hour cultivation could reduce the viability of these tumor cells by $25 \%$. In addition, as the concentration increases, the lethality of the drug increases. The concentrations of $100 \mu \mathrm{m}$ in both drugs reduced cell viability by more than $50 \%$. The results of the present study showed the effects of flunixin and Ginkgo biloba on the A2780s cell line, which causes the expression of the BIM gene and its increase, increased over time, indicating the difference between the groups at a significant level (Figure 4).

The results showed the interaction and synergy of both drugs on the A2780s cell line, which either affects one drug and the effect of another drug after about 24 hours of effect on the cancer cell multiplied. The expression of the BIM gene in the cell lines treated with Ginkgo biloba, exposed to the drug for $48 \mathrm{~h}$, significantly increased in comparison to that reported for $24 \mathrm{~h}$ (Figure 4 and 5). The aforementioned findings are also consistent with the results of a study performed by Jiang et al. showing that Ginkgo biloba extract could have anticoagulant and apoptotic effects on ovarian cancer cells (5). According to the aforementioned study, it can be said that Ginkgo biloba is effective as an antiinflammatory agent and inhibitor of apoptosis and can be helpful in the treatment of ovarian cancer $(9,10)$. The onset of apoptosis is due to cell surface receptors, such as Fas receptors and tumor necrosis factor receptor 1 (external pathway), various genotoxic agents, metabolic toxins, or transcriptional signals (intrinsic pathway), which cause apoptosis (11). 


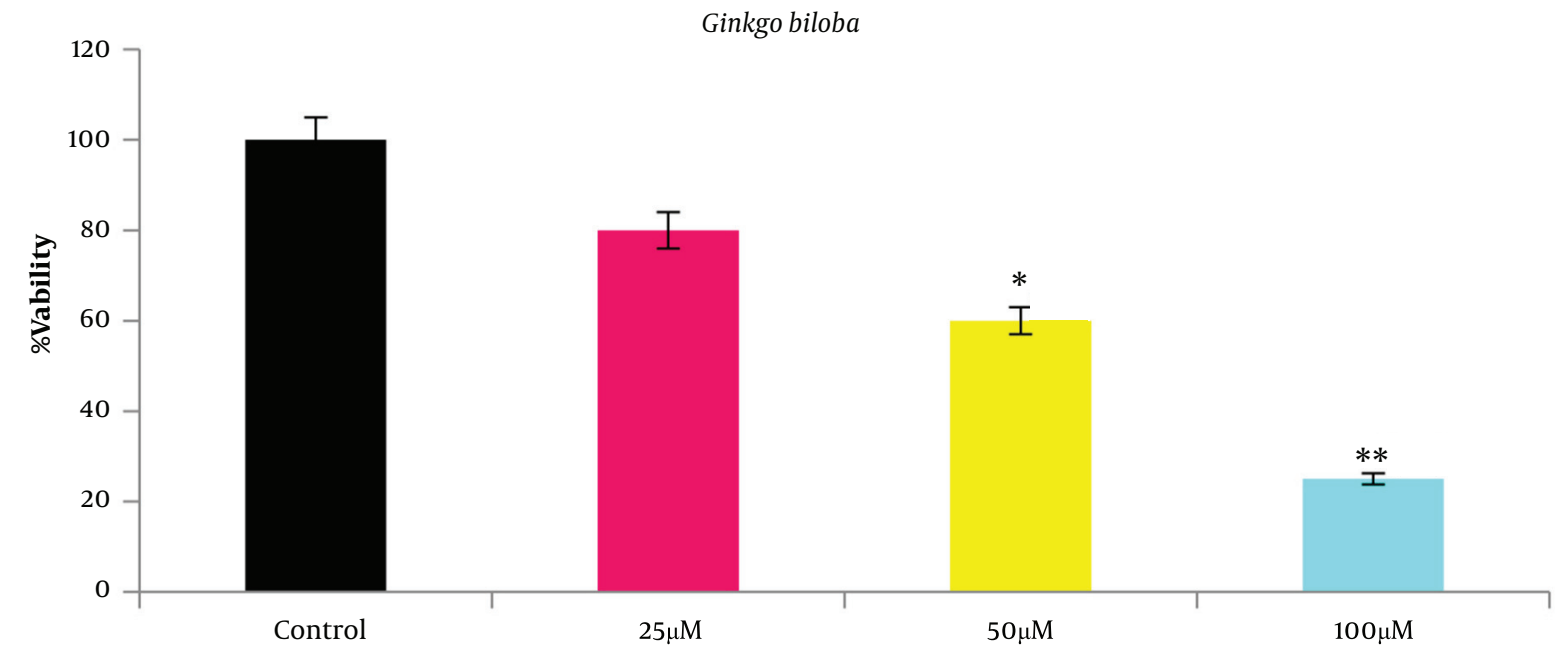

Figure 1. Significance of cell viability of A2780S cell line at different concentrations of Ginkgo biloba for $24 \mathrm{~h}$ of treatment compared to that of control group; ${ }^{*} \mathrm{P}<0.01$ and $\mathrm{P}<$ 0.01 vs. control group.

IC50; 4.40769

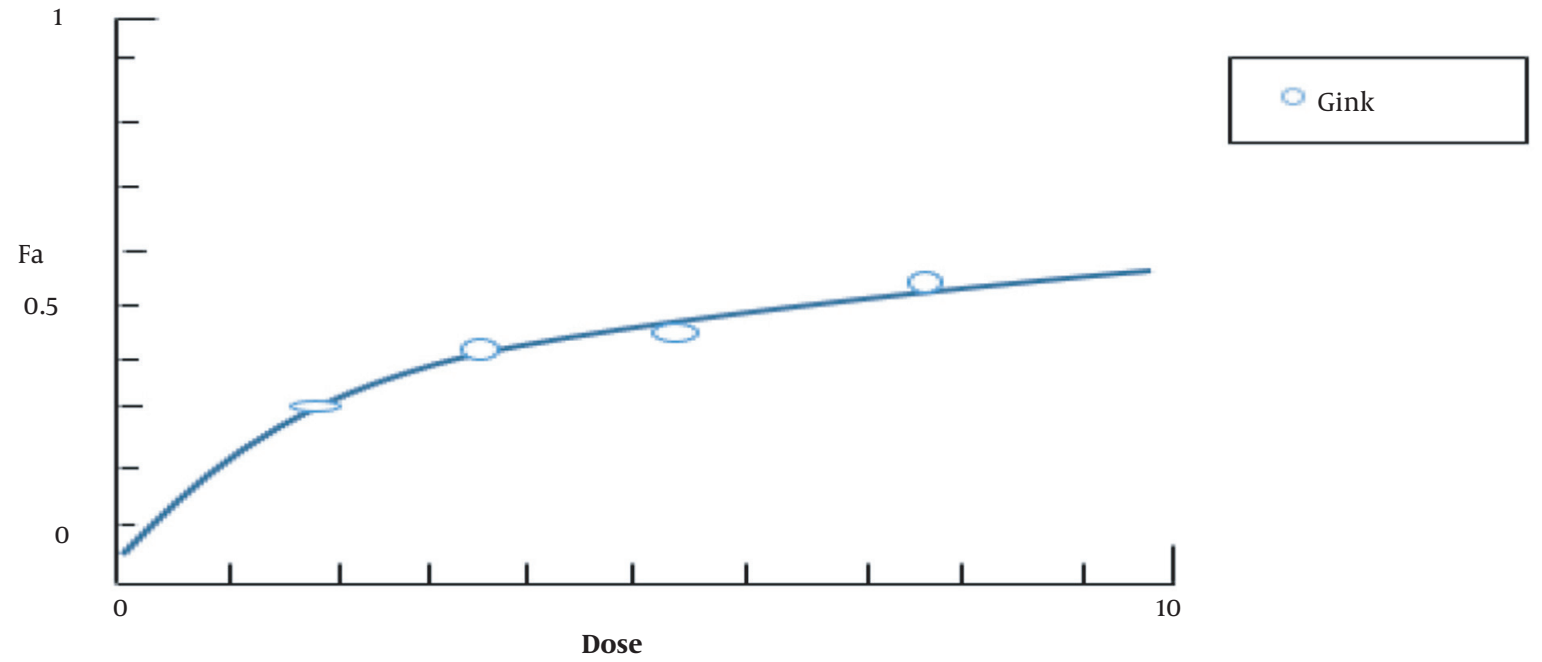

Figure 2. Calculation of half-maximal inhibitory concentration (IC50) for Ginkgo biloba by CompuSyn Software (combination index $<4.2$ )

Cytochrome $\mathrm{C}$ secretion and mitochondrial cleavage lead to the activation of caspase-9 and caspase-3(12). The external pathway can bypass the mitochondrial stage, leading to cell destruction $(13,14)$. This protein induces apoptosis by inhibiting the anti-apoptotic members of this family and plays an essential role in tumor cell biology. Decreased BIM expression is effective in increasing cell proliferation and metastasis of cancer cells (15). Ginkgo biloba inhibits cell cycle in phase Go/G1 to phase S (14). Ginkgo biloba and its components, such as quercetin and ginkgolides, are effective in numerous cancers, such as bladder and breast cancers, by increasing antioxidant activity through various pathways (16).

Flunixin reduces anaplasia and cell proliferation by inhibiting cyclooxygenase by reducing epithelial growth factor $(16,17)$. On the other hand, cyclooxygenase by reducing p53 of tumor suppressor gene reduces cell arrest in the G1 stage (18). In most cancers, p53 levels in the cyto- 


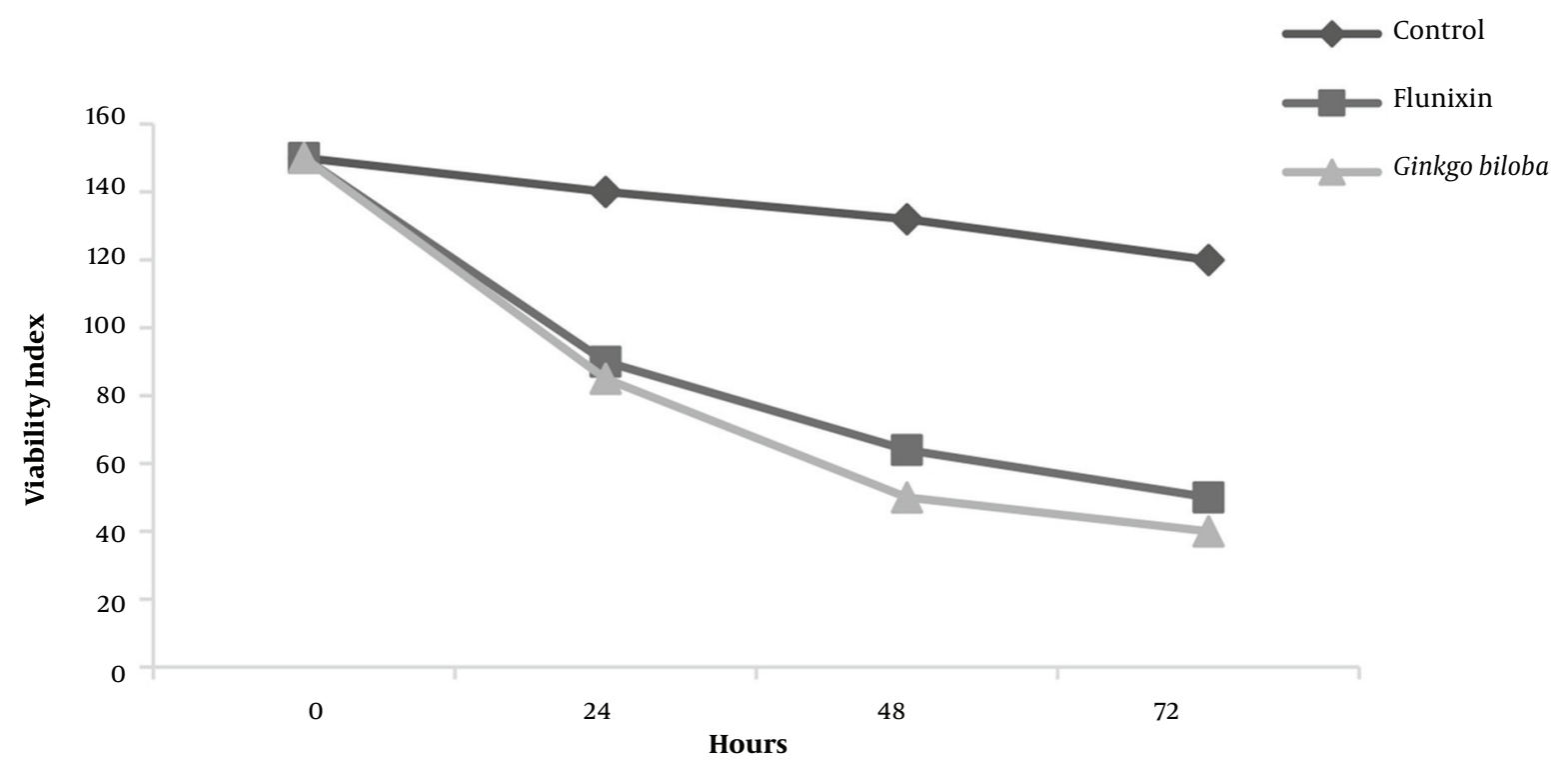

Figure 3. Cell viability of A2780S cell line at different times indicating the highest decrease in cell count in $24 \mathrm{~h}$; ${ }^{*} \mathrm{P}<0.01 \mathrm{vs.} \mathrm{control} \mathrm{group.}$

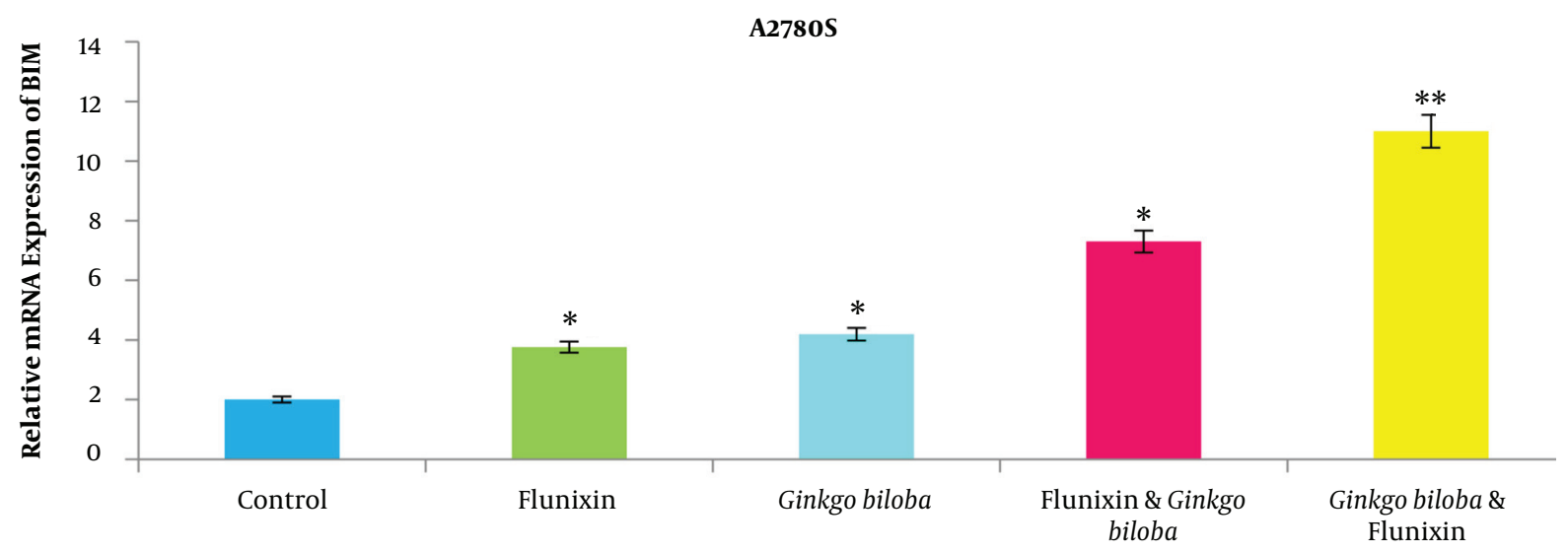

Figure 4. Changes in BIM gene expression in A2780S cell line with concentration of $100 \mu \mathrm{m}$ for flunixin and Ginkgo biloba in $24 \mathrm{~h}$ indicating a significant difference compared to that of control group; ${ }^{*} \mathrm{P}<0.01$ vs. control group.

plasm increase with increasing cyclooxygenase. In addition, when inhibitors are removed from P53, it will function to kill cells $(17,18)$. Cyclooxygenase increases the production of an enzyme called aromatase by producing E2type prostaglandins (18). This enzyme, known as CYP19, is one of the enzymes in cytochrome P450 and can convert endogens to estrogen. Since estrogen induces increased tumor growth (19), estrogen levels might decrease and inhibit tumor growth by the inhibition of aromatase by cyclooxygenase inhibitors. The inhibition of apoptosis by various $(17,20)$, such as the inactivation of tumor necrosis factor receptor (14), increased expression of anti-apoptotic protein BCL2 (20), and increased anti-apoptotic protein, prevents the mitochondrial membrane from releasing cytochrome $\mathrm{C}$ into the cytocell; finally, apoptosis will not occur $(20,21)$. In a study performed by Keramati et al., nonselective cyclooxygenase inhibitors and compounds called celecoxib, which are selective COX-2 inhibitors, were effective in the inhibition and treatment of breast cancer (10).

Since nonsteroidal anti-inflammatory drugs, such as aspirin, indomethacin, and ibuprofen, act as nonselective cyclooxygenase inhibitors and flunixin is a nonsteroidal 
Dose Effect Curve

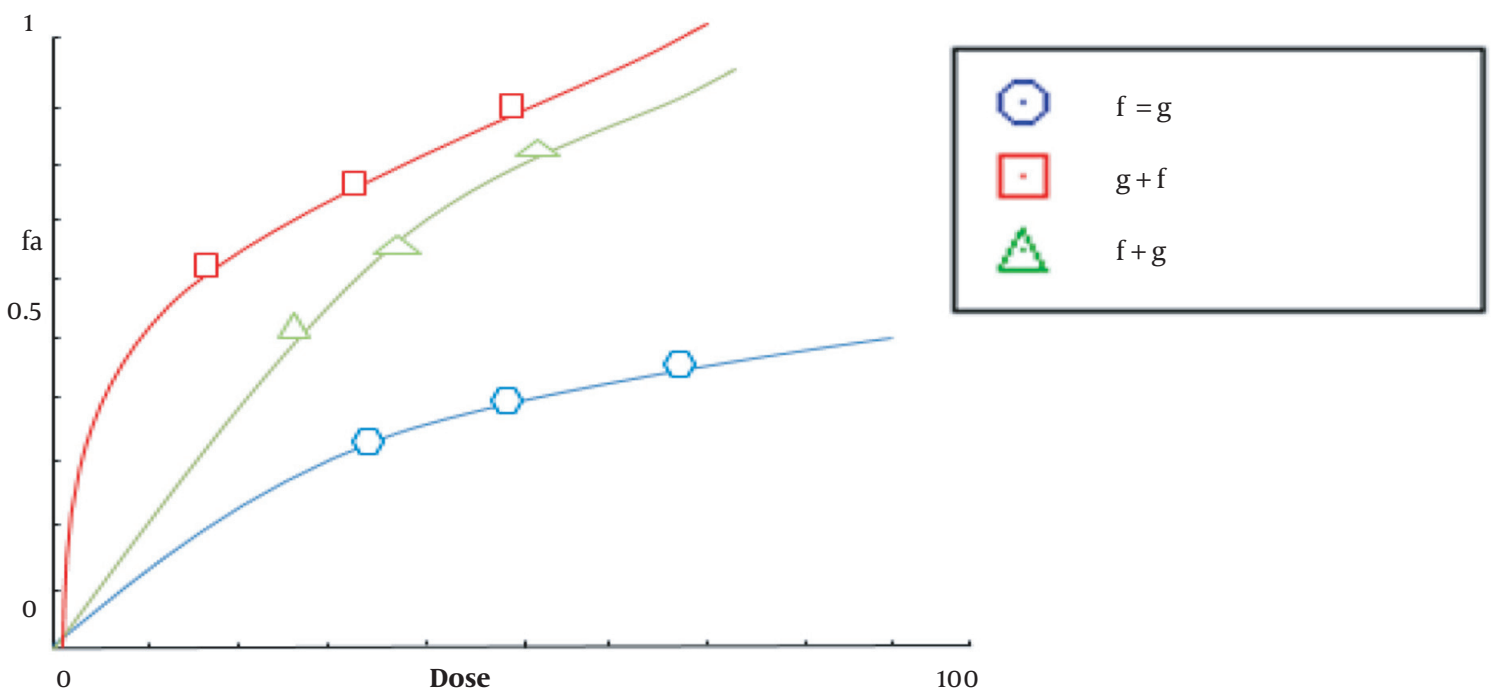

Figure 5. Logarithmic dose-effect curve for drug synergism of Ginkgo biloba and flunixin using CompuSyn software

anti-inflammatory drug, the results showed that flunixin had a positive effect on the treatment and prevention of cancer. Microscopic results obtained from drug-receiving groups showed that cancer cells are degenerating, to the point that the cells are regaining their regular order.

\subsection{Conclusion}

Ginkgo biloba and flunixin have an inhibitory effect on the survival of ovarian cancer cells (the A2780s cell line) in a dose-dependent and time-dependent form. Ginkgo biloba and flunixin also increase BIM gene expression in A2780s cells. The present study confirms previous studies and promises that Ginkgo biloba and flunixin have toxic effects on ovarian cancer cells, the A2780s cell line. Furthermore, Ginkgo biloba and flunixin compounds can be used to develop ovarian anti-cancer drugs.

\section{Footnotes}

Authors' Contribution: Farnoosh Soleamani, Elham Salehi, and Majid Morovati-Sharifabad contributed to the conception and design of the experimental work. Fatemeh Sarkargar and Gholamhosein Pourghanbari contributed to data analysis.

Conflict of Interests: There was no conflict or competing financial interests.

Ethical Approval: IR.YAZD.REC.1399.048

Funding/Support: The present study financially supported by Yazd University, Iran.

\section{References}

1. Stakleff K, Von Gruenigen VE. Rodent models for ovarian cancer research. Int J Gynecol Cancer. 2003;13(4):405-12. doi: 10.1046/j.15251438.2003.13317.x.

2. Piek JM, van Diest PJ, Verheijen RH. Ovarian carcinogenesis: An alternative hypothesis. In: Coukos G, Berchuck A, Ozols R, editors. Ovarian cancer. Advances in experimental medicine and biology. 622. New York, NY: Springer; 2008. p. 79-87.

3. Forouzandeh F, Salimi S, Naghsh N, Zamani N, Jahani S. [Evaluation of anti-cancer effect of Peganum harmala $\mathrm{L}$ hydroalcholic extract on human cervical carcinoma epithelial cell line].J Shahrekord Univ Med Sci. 2014;16(4):1-8. Persian.

4. Pignata S, Scambia G, Katsaros D, Gallo C, Pujade-Lauraine E, De Placido S, et al. Carboplatin plus paclitaxel once a week versus every 3 weeks in patients with advanced ovarian cancer (MITO-7): a randomised, multicentre, open-label, phase 3 trial. Lancet Oncol. 2014;15(4):396-405. doi: 10.1016/s1470-2045(14)70049-x.

5. Jiang W, Cong Q, Wang Y, Ye B, Xu C. Ginkgo may sensitize ovarian cancer cells to cisplatin: Antiproliferative and apoptosis-inducing effects of ginkgolide B on ovarian cancer cells. Integr Cancer Ther. 2014;13(3):NP10-7. doi: 10.1177/1534735411433833. [PubMed: 22505596].

6. Rezazadeh S, Yazdani D, Ataee P, Pirali - Hamedani M, Taghizad - Farid R. [Study on seasonal variation of flavonoids in Ginkgo biloba L. cultivated in Iran].J Med Plant. 2007;6(21):11-9. Persian.

7. Mollaei H, Safaralizadeh R, Babaei E, Abedini MR, Hoshyar R. The anti-proliferative and apoptotic effects of crocin on chemosensitive and chemoresistant cervical cancer cells. Biomed Pharmacother. 2017;94:307-16. doi: 10.1016/j.biopha.2017.07.052. [PubMed: 28763753].

8. Kleinhenz MD, Gorden PJ, Smith J, Schleining JA, Kleinhenz KE, Rea D, et al. 21 evaluation of transdermal flunixin meglumine on experimentally induced lameness in adult dairy cattle. J Anim Sci. 2018;96(suppl_2):11. doi:10.1093/jas/sky073.019. 
9. Gee J, Lee IL, Jendiroba D, Fischer SM, Grossman HB, Sabichi AL. Selective cyclooxygenase-2 inhibitors inhibit growth and induce apoptosis of bladder cancer. Oncol Rep. 2006;15(2):471-7. [PubMed: 16391871].

10. Keramati K, Abbas Nia VS, Pazireh N, Alipour H. [The effect of flunixin as a nonselective inhibitor of cyclooxygenase enzymes on the prevention and treatment of mammary gland cancer in female Wistar rats] J Ofogh Danesh Sci Res. 2010;15(4):24-32. Persian.

11. Shuang T, Shi C, Chang S, Wang M, Bai CH. Downregulation of miR17\&\#126;92 expression increase paclitaxel sensitivity in human ovarian carcinoma SKOV3-TR30 cells via BIM instead of PTEN. Int J Mol Sci. 2013;14(2):3802-16. doi: 10.3390/ijms14023802. [PubMed: 23396109]. [PubMed Central: PMC3588071].

12. Kelly JP, Kaufman DW, Kelley K, Rosenberg L, Anderson TE, Mitchell AA. Recent trends in use of herbal and other natural products. Arch Intern Med. 2005;165(3):281-6. doi: 10.1001/archinte.165.3.281. [PubMed 15710790].

13. Wei EH, Rao MR, Ji ND, Chen XY, Chen Q. [Inhibitory effects of ginkgolide B on proliferation of bovine aortic smooth muscle cells]. Yao Xue Xue Bao. 2002;37(2):90-3. Chinese. [PubMed: 12579949].

14. Zheng S, Zhou Z. A new Mesozoic Ginkgo from western Liaoning, China and its evolutionary significance. Rev Palaeobot Palynol. 2004;131(1-2):91-103. doi:10.1016/j.revpalbo.2004.03.002.

15. Gately S. The contributions of cyclooxygenase-2 to tumor angiogenesis. Cancer Metastasis Rev. 2000;19(1-2):19-27. doi: 10.1023/a:1026575610124. [PubMed: 11191059].

16. Chang L, Liu T, Chai Z, Jie S, Li Z, Liu M, et al. lincRNA-p21 mediates the anti-cancer effect of Ginkgo biloba extract EGb 761 by stabilizing E-cadherin protein in colon cancer. Med Sci Monit. 2018;24:948896. doi: 10.12659/MSM.911924. [PubMed: 30594943]. [PubMed Central: PMC6322715].

17. Barbas CF, Burton DR, Silverman GJ. Phage display: A laboratory manual. Cold Spring Harbor Laboratory Press; 2004.

18. Nurse P. A long twentieth century of the cell cycle and beyond. Cell. 2000;100(1):71-8. doi: 10.1016/s0092-8674(00)81684-0.

19. Zhu YM, Azahri NS, Yu DC, Woll PJ. Effects of COX-2 inhibition on expression of vascular endothelial growth factor and interleukin-8 in lung cancer cells. BMC Cancer. 2008;8:218. doi: 10.1186/1471-2407-8-218. [PubMed: 18671849]. [PubMed Central: PMC2516523].

20. Reid BM, Permuth JB, Sellers TA. Epidemiology of ovarian cancer: A review. Cancer Biol Med. 2017;14(1):9-32. doi: 10.20892/j.issn.20953941.2016.0084. [PubMed: 28443200]. [PubMed Central: PMC5365187].

21. Saffari-Chaleshtori J, Jamali N, Heydari E, Ghatreh Samani K. [Molecular dynamics simulation study of the effect of hesperetin on preapoptotic factorsof Bad, Bak, and Bim]. Sci J Kurdistan UnivMedical Sci. 2019;23(6):1-9. Persian. 